This item was submitted to Loughborough's Research Repository by the author.

Items in Figshare are protected by copyright, with all rights reserved, unless otherwise indicated.

\title{
Documentation in the neonatal unit: The support given to parents and their participation in their baby's care.
}

PLEASE CITE THE PUBLISHED VERSION

https://doi.org/10.1111/jan.13910

\section{PUBLISHER}

(c) Wiley

\section{VERSION}

AM (Accepted Manuscript)

\section{PUBLISHER STATEMENT}

This is the peer reviewed version of the following article: SHAW, C. ... et al., 2018. Documentation in the neonatal unit: The support given to parents and their participation in their baby's care. Journal of Advanced Nursing, 75 (3), pp.628-639, which has been published in final form at https://doi.org/10.1111/jan.13910. This article may be used for non-commercial purposes in accordance with Wiley Terms and Conditions for Use of Self-Archived Versions.

\section{LICENCE}

CC BY-NC-ND 4.0

\section{REPOSITORY RECORD}

Shaw, Chloe, E. Suonpera, Katie Gallagher, Narendra Aladangady, Elizabeth Stokoe, and Neil Marlow. 2019. "Documentation in the Neonatal Unit: The Support Given to Parents and Their Participation in Their Baby's Care.". figshare. https://hdl.handle.net/2134/35204. 
PARENTAL SUPPORT AND PARTICIPATION IN THE NEONATAL NOTES

Documentation in the neonatal unit: the support given to parents and their participation in their baby's care

Shaw, C., Suonpera, E., Gallagher, K., Aladangady, N., Stokoe, E., \& Marlow, N. (in press). Documentation in the neonatal unit: The support given to parents and their participation in their baby's care. Journal of Advanced Nursing.

\begin{abstract}
Aims: To explore how often the participation of parents in their infants' care and professionals' support for parents was documented in the clinical records and to determine how such participation and support were documented.

Background: Comprehensive documentation can facilitate collaboration between parents and health care professionals, supporting family-centered care, yet little is known about how this is reflected in practice.
\end{abstract}

Design: A prospective, mixed methods approach was used to analyse the clinical records of newborns.

Methods: The study was carried out in a large tertiary Neonatal Unit in the United Kingdom, from 2013-2014. We analysed the clinical records of 24 critically ill newborns using content analysis and thematic analysis, enabling us to determine the frequency of documented support and participation as well as how these were documented.

Results: We identified four categories of support in the clinical records: emotional, spiritual, social and practical support. We also identified instances where parents were encouraged to 


\section{PARENTAL SUPPORT AND PARTICIPATION IN THE NEONATAL NOTES}

participate in their infant's care. Frequency differences in the documentation of support between infants facing a redirection of care decision and infants receiving active treatment were found. Two organisational themes were identified: task focused documentation and minimal documentation of parental role. These were grouped together under the global theme professional accountability. The perspectives and experiences of parents were minimally documented throughout.

Conclusion: Documentation of support towards parents and parents' participation in their infants' care was limited in terms of frequency and content. Encouraging regular, detailed documentation of these aspects of care may facilitate family-centered care.

Keywords. Documentation, family-centered care, neonatal, support, participation, nursing, thematic analysis, content analysis, parents 


\section{SUMMARY STATEMENT}

Why is this research or review needed?

- There has been minimal research into how support for parents by the health care professionals and parents' participation in their infant's care is documented in NICU.

- The documentation of support that is given to parents, has important implications for promoting collaboration between parents and health care professionals.

What are the key findings?

- The perspectives and experiences of parents were minimally reported throughout the clinical records.

- Support for parents and their participation in their infant's care tended to be documented for the main purpose of professional accountability as opposed to familycentered care.

How should the findings be used to influence policy/practice/research/education?

- Change in documentation practices should be encouraged as detailed documentation of parental experiences and preferences may promote a culture of improved interaction between parents and the health care team.

- By improving interactions between parents and the health care team, infant and parent outcomes may ultimately be improved.

- Future research could investigate the design and use of clinical record proformas and parental recording of care, to facilitate a more comprehensive documentation of parental preferences and experiences. 
PARENTAL SUPPORT AND PARTICIPATION IN THE NEONATAL NOTES

\section{INTRODUCTION}

Family-centered care is recognized internationally to be an important part of neonatal intensive care, with important implications being identified for both the parents and the baby (Landsem, Handegard, Tunby, Ulvund, \& Ronning, 2014; Woodward et al., 2014; O'Brien et al., 2018). The documentation of parental participation in their baby's care, as well as their preferences and experiences, is arguably an important component in ensuring care is tailored to the individual needs of the family and yet little is known about how families' experiences and preferences are documented in practice.

\section{BACKGROUND}

Historically, the primary focus of neonatal care has been reducing infant mortality and morbidity. Less attention has been given to the psychosocial needs of families (POPPY, 2009). More recently however, the concept of family-centered care, defined as involving families in all aspects of the infant's care and treatment (Gooding et al., 2011; Harrison, 1993; POPPY, 2009;), has gained support and prompted endorsement from institutions such as the American Academy of Pediatrics (AAP, 2003) and the National Institute of Clinical Excellence (NICE, 2010). These organizations emphasize collaboration with parents and acknowledge the need to tailor services to individual family needs and desires (Griffin, 2006; POPPY, 2009; Ramezani, Shirazi, Sarvestani, \& Moattari, 2014). Nurses in particular, are in an ideal position to offer practical and emotional support and guidance to parents. The type of support nurses can provide ranges from helping parents to learn how to care for their hospitalized infant (such as breastfeeding and kangaroo care); how to engage siblings with the hospitalized infant; facilitating effective communication and decision making between different health professionals working with the family; and providing one to one 


\section{PARENTAL SUPPORT AND PARTICIPATION IN THE NEONATAL NOTES}

psychological support for parents in emotionally challenging situations. Evidence to support this approach has grown alongside these recommendations and has provided insight into the mental health of parents following admission of their newborns to the Neonatal Intensive Care Unit (NICU) (Lefkowitz, Baxt, \& Evans, 2010; Shaw, Bernard, Storfer-Isser, Rhine, \& Horwitz, 2013), parents' experiences during their infants' stays in the NICU (Smith, Steel, Fisher, Salhi, \& Shen, 2013; Stacey, Osborn, \& Salkovskis, 2015; Van der Pal, Alpay, van Steenbrugge, \& Detmar, 2014), and parents' decision-making processes for critically ill infants (de Boer, van Blijderveen, van Dijk, Duivenvoorden, \& Williams, 2012; SudiaRobinson \& Freeman, 2000; Van Manen, 2014).

Documentation by health care professionals (HCPs) in the clinical record can help to promote collaboration with parents by providing information about how the infant and family are supported as well as their preferences and needs. It also provides important insight into how parents establish their parental roles and how their preferences are understood. In 1993, Hurst called for a more comprehensive documentation of parents' perceptions and preferences in neonatal care to enable "nurses to develop a more substantive assessment of parental participation and devise interventions to support beneficial parental participation" ( $\mathrm{p}$. 88). Through documentation of parental experiences and participation, care can be tailored to the specific needs of families, maximizing the possibility of family-centered care. During neonatal intensive care, where infants are treated by interdisciplinary teams, the clinical record is instrumental in facilitating communication and providing the possibility of familycentered care. Verbal handovers are less effective because information may be missed or lost in the process (Hegarty et al., 2005). HCPs are also professionally bound to maintain clear and accurate records (General Medical Council, 2013; Nurse and Midwifery Council, 2015). 


\title{
PARENTAL SUPPORT AND PARTICIPATION IN THE NEONATAL NOTES
}

Few descriptions of the documentation process can be found in the literature, and existing reports focus on specific areas of interest, such as documentation of time for skin-toskin contact (Blomqvist, Rubertsson, Nyqvist, 2011) or interdisciplinary support (Carter et al., 2004). In one report of professional support during end-of-life care, parent participation in decision making was not recorded in three of 18 cases, and few case notes indicated that emotional support was provided (Abe, Catlin, Mihara, 2001). Thus, it is frequently unclear from the clinical records whether parents received the necessary support at these critical times. In light of this fact, we undertook a review of case records for a group of neonates enrolled in a prospective study of critical care decision making. Because of the exploratory nature of this study, given the limited research in the area, we took a mixed method approach to more fully capture the frequency of documentation as well as the nature of that documentation.

\section{THE STUDY}

\begin{abstract}
Aims
The aim of the study was to determine how often the participation of parents in their infants' care and professionals' support for parents was documented in the clinical records of infants and to determine how such participation and support were documented.
\end{abstract}

\section{Design}

A prospective, mixed method design was adopted. Analysis involved both quantitative content analysis and qualitative thematic analysis; systematically approached using the steps outlined by Marks and Yardly (2004). Quantitative analysis was used to identify frequency counts of different types of support and parental participation in care. 
PARENTAL SUPPORT AND PARTICIPATION IN THE NEONATAL NOTES

Qualitative analysis provided a deeper exploration of how support was documented as a whole.

\section{Sample/Participants}

Participants were recruited from a large 46 bed tertiary NICU in the UK from July 2013 to April 2014. A purposive sampling approach was used to recruit 25 families whose infant was critically ill. Families were eligible if their infant had been or were likely to be at the center of a conversation regarding the limitation of life sustaining treatment. Families were introduced to the study by a HCP and a meeting with a member of the research team was arranged for interested parents. The sample size was considered sufficient for the purpose of using descriptive statistics and for thematic saturation due to the extensive volume of clinical records anticipated.

Infants who were recruited to the study had a study sticker on their clinical notes so that the clinical and research team were able to identify the baby for the different components of the study. In particular, it reminded the doctors to audio record any conversations they had with the family that were away from the cot side.

\section{Data Collection}

An audit tool was used to collect basic information about the clinical records documenting all instances where the parents were mentioned: date and time, location in the notes and what was actually said. Table 1 provides an example of the audit tool being used to collect data for one of the families. For the communication sheets we also recorded who was present. Two researchers (CS, SK) manually recorded this information. 


\section{PARENTAL SUPPORT AND PARTICIPATION IN THE NEONATAL NOTES}

The hand-written clinical records consisted of 1) clinical summaries; 2) nursing notes; and 3) communication sheets. The clinical summaries were completed by the physicians and focused on the infants' clinical condition and medical care plan. The nursing notes were completed by the nurses and focused on all care provided as well as details of family visitation. Entries were made either once or twice a day depending on the infant's condition. The communication sheets were completed by physicians, nurses, and other professionals who had significant conversations with the parents. Post hoc, we limited analysis to the nursing notes and the communication sheets. Support was scarcely documented in the clinical summaries, as the primary purpose was to record clinical details. The unit provided no written guidelines for writing in the infant's notes.

In addition to free hand-written nursing notes, a checklist was used by nurses once or twice a shift to indicate when a commonly occurring nursing task was performed. The checklist included: 1) keep parents up to date with care; 2) encourage siblings to visit as per unit policy; and 3) encourage parental participation in care as condition allows. The statement referring to parental participation was specifically relevant to this study and its prevalence included in analysis.

\section{Ethical considerations}

The study received approval from the local Research Ethics Committee and Research and Development Department from the participating National Health Service Trust. Parents gave written informed consent for participation in the study; names and identifying details have been replaced with pseudonyms. Health care professionals gave consent for having their audio conversations recorded but consent was not needed for auditing the notes as this involved the collection of routine clinical data. 
PARENTAL SUPPORT AND PARTICIPATION IN THE NEONATAL NOTES

\section{Data Analysis}

Content analysis. A coding frame was developed to distinguish different types of support given to parents and identify parents' participation in their infant's care (Table 2). This was achieved through an iterative process but also guided by categories used in the literature, including emotional support (POPPY, 2009).

Quantitative data were exported from NVivo and analyzed using STATA 13 software. Summary statistics were prepared including the frequency of references for each support category and participation in care, the overall distribution of support and participation, and total days in care. The frequency of references for each category, were compared for parents who had a discussion concerning limiting life sustaining treatment (LLST) while in the NICU, with those parents whose infant received active care (the active care group). As the needs of parents may change according to the severity of the infant's health, we considered it important to determine whether the frequency and type of support documented differed according to these two groups.

Thematic analysis. In the second stage of analysis, the codes were analyzed thematically to find "repeated patterns of meaning" across codes (Braun \& Clarke, 2006:15). Thematic analysis seeks to identify, analyze and interpret patterns at different levels of text within qualitative data (Attride-Stirling, 2001; Fereday \& Muir-Cochrane, 2006). We first sought to identify basic themes representing specific aspects or issues in the text (Gallagher, Porock, Edgley 2010). We then categorized these basic themes into organizational themes, which summarized the main principles in each. These organizational themes were then grouped under a global theme, representing the data as a whole (Attride-Stirling 2001). The themes and their hierarchical organization are shown in Figure 1. 


\section{PARENTAL SUPPORT AND PARTICIPATION IN THE NEONATAL NOTES}

\section{Validity and Reliability/Rigour}

Our audit tool recorded data in an inductive way, preserving exactly what was said about the parents. Our coding frame was refined through inter-rater comparisons (CS, ES); operationalizing the codes in a way that was "transparent, coherent and understandable" (Marks \& Yardley, 2004: 63). The thematic network was developed through a rigorous iterative process of rereading of codes and themes and discussions between researchers (CS, $\mathrm{ES}, \mathrm{KG})$.

\section{FINDINGS}

Of 25 enrolled families, 3 were excluded due to missing communication sheets or nursing notes. The remaining 22 families included 24 infants; 14 singletons and 10 twins. Of the eight families with twins: 2 families included both twins; 2 included 1 twin as the second was not eligible for participation (being clinically stable); 4 families had only one surviving twin. Parents of 7 infants had LLST conversations with the physicians while in NICU. The main clinical problems included extreme prematurity; major congenital anomalies, severe neonatal encephalopathy at term and other critical conditions (surgical, respiratory, growth, and neurological concerns). The LLST group infants' main clinical conditions were more commonly other than prematurity and therefore their average gestational age at birth and birth weight were higher than the infants who received active care ( 28 weeks vs. 25 weeks and $1612 \mathrm{~g}$ vs. $1151 \mathrm{~g}$ respectively). Overall 15 infants were males. Median length of stay was 65 days (range 4 to 232 days) (Table 3). Three infants died, having had a decision against active resuscitation in case of acute deterioration, one of whom was referred to palliative care services. 
PARENTAL SUPPORT AND PARTICIPATION IN THE NEONATAL NOTES

\section{The participation of parents in their infants' care and professionals' support for parents: the frequency of mentions in the infant's clinical records}

Overall distribution of support for parents. The data comprise 1694 days of care across all sets of clinical records. The nursing notes and communication sheets consisted of 1280 direct references to the support for parents by the HCPs and parents' participation in their newborns' care; less than one reference per day. The majority were found in the nursing notes $(81 \%)$, where parents' participation in care was most frequently noted $(86 \%)$. The next most prevalent type of documentation was emotional support (19\%) (Table 4). These entries were less frequent, and they mostly consisted of short references to parents' feelings or creating memories. Some record of emotional support for parents or parents' participation in care occurred in all infants' notes (24/24). Records of practical support (16/24), social support (11/24), or spiritual support (7/24) provided to parents were less common.

In the nursing notes, in addition to references in hand written entries, a checkbox for the statement 'encourage parental participation in care as condition allows' was used. These were not included in the frequency counts above, but were counted separately, appearing 506 times in total. As a comparison, in only 16 entries did the nurses write having encouraged the parents to perform a specific activity such as express breast milk for the infant.

Limiting life support. Seven sets of parents had a discussion concerning limitation of life sustaining treatment for their infants while in the NICU (LLST group). In the remaining 17 cases, the infants received active treatment (active care group). References concerning spiritual support were more frequent in the infants' records among the LLST group (21 vs. 0.07 references per 100 care days respectively). In addition, emotional support (43 vs. 21), practical support (34 vs. 6), and social support (6 vs. 2) of parents occurred more frequently 


\section{PARENTAL SUPPORT AND PARTICIPATION IN THE NEONATAL NOTES}

in the records of the LLST group. In contrast, documentation of the participation of parents in their infant's care was more frequent among the active care group (73 vs. 56) (Figure 2).

\section{How participation of parents in their infants' care and professionals' support for parents was documented in the infant's clinical records}

We identified six basic themes which represented how HCPs documented the support provided to parents as well as parents' participation in their newborns' care. These were categorized into two organizational themes: 1) task focused reporting, categorized by the basic themes of offering resources, offering services and offering emotional support; and 2) minimal documentation of parental role categorized by the basic themes of limited documentation of parents' feelings, experiences and preferences, activity focused documentation of care and outcome focused documentation of decisions. These two organizational themes were grouped under a global theme of professional accountability (Figure 1). Each of the organizational themes and basic themes are discussed sequentially, and where quotes are provided, they are given alongside the participating family's ID, e.g. $\mathrm{F}$ (family)1T(twin)2.

\section{Task focused reporting}

In the majority of records, support for the parents by the HCPs was documented in terms of the professionals' actions; offering resources, services and emotional support.

Offering resources. Documentation of support focused on practical tasks concerning the provision of resources to parents, including offering the parents accommodation. In the communication sheets, the family room was documented as an option that could be provided to the parents at the beginning of their infant's care: "To provide family room for mother to stay (to encourage expressing breast milk) if room available" F1. Practical support also 


\section{PARENTAL SUPPORT AND PARTICIPATION IN THE NEONATAL NOTES}

included the documentation of information resources being provided on occasion including DVDs or booklets explaining prematurity: "Parents have been given small wonders DVD \& preterm infant booklet..." F3. Most commonly these were given soon after the infant's admission. Additional information was also documented on occasion including copies of infant's medical records such as MRI reports or blood test results, and written information about kangaroo care and breastfeeding. In general, this documentation tended to be brief and about the activity of the HCP providing something practical and physical to the parents, as opposed to documenting the expressed needs or experiences of the families.

Offering services. In addition to practical resources, in the communication sheets, HCPs routinely documented instances where they offered a service. In two cases, changes to visiting policies were documented to allow other than close family members to accompany the parent: "Mum has identified that she is a single parent $\&$ is worried about access following (date) ... I have indicated that we will discuss her situation and make a plan” F5. Wider social support included a referral to a General Practitioner, referral to community support, referral to bereavement support, and mentions of support from the Bliss (a special care baby charity) parent group. References to various types of social support tended to be brief, infrequent, and limited to the mention of their occurrence. Spiritual support was similarly documented in the communication sheets as a service provision: of a priest, prayers or baptism, and whether it had been taken up by the parents: "offered parents that we can arrange religious support (through our chaplains), if they wish to access it” F29. Brief documentation of staff undertaking memory making activities regularly appeared in the nursing notes in particular, including: taking photos, making footprints, and providing memory boxes: “...memory journey box given” F8.

Offering emotional support. When documenting emotional support to parents, references tended to focus on how the HCP resolved the situation or activity as opposed to 


\section{PARENTAL SUPPORT AND PARTICIPATION IN THE NEONATAL NOTES}

documentation of individual family needs, wishes and emotions. It was often limited to the parents' participation in care rather than concerning the parents' emotions more specifically, including 'encouragement' to express breast milk in the communication sheets: "Encouraged Mum to start expressing milk if she is feeling better" F12T1. There were some minimal references in the notes that 'reassurance' was given to the parents that the infant is stable, or things are normal: "Explained extubation failed due to high $\mathrm{O} 2$ requirement. Will retry if indicated tomorrow. Reassured that this can happen at this stage” F6. In the nursing notes there were occasions where a difficult situation was documented, however more specific details of how the professional supported the parent were not recorded: For example: "Mum stayed overnight, was very upset - spoke to mom [sic] and reassured her...." F12T2.

This unidirectional focus was also seen in the support offered to parents during and after the death of their infant, for example when enabling parents to create memories "Photos and footprints done" F22. The documentation of emotional support was limited to condolences or comfort being given in a unidirectional way: "Comfort given to mum and allowed her to cuddle her baby in the bereavement room" F1. When it was documented that parents' experiences and feelings were explored, it was often limited to entries by a support therapist. This included occupational health therapists, speech and language therapists, the hospital counsellor, and breast-feeding nurse: "We explored issues around loss, planning funeral and some closure to enable them as a family to move on" F6. The use of checkboxes in the nursing notes (as reported above) also represents this unidirectional approach.

\section{Minimal documentation of parental role}

Across the records, the parents' role was given minimal attention. Mentions and details of parental involvement in cares and decisions tended to be focused on what was done rather than providing insight in to the parents' experiences. 
PARENTAL SUPPORT AND PARTICIPATION IN THE NEONATAL NOTES

Limited documentation of parents' feelings, experiences and preferences. The

references to parents' feelings were generally brief and infrequent. Documentation of positive emotions tended to be limited to being 'happy' and accompanied generic statements that the infant is well: "Mum $\&$ dad were fully updated about the progress $\&$ are happy with the baby's progress" F12T2, or that the parents are happy with the care plan: “.... Parents informed and aware of change in treatment. Happy with plan" F12. More detailed reports on positive feelings were seen in two instances as reported by a support therapist: "Both very pleased about transfer and delighted to be able to do more with Peter. Dad more relaxed in the quieter environment...." F4.

While there was some specification in the notes about what the parents were upset or anxious about and that reassurance was given, these entries tended to be infrequent and brief and presented as discrete occurrences: "Mum very concerned $\&$ anxious which is understandable due to twin one's sudden death. I reassured her that Timmy is currently stable and ventilated" F11. More detailed entries were infrequent and tended to be made by a support therapist: "Discussion with mum \& grandmother. Explained how they were both coping, discussed Tommy at length (deterioration + subsequent death). Fear of handling Timmy addressed by encouraging kangaroo care and detailing the benefits..." F11.

Parental preferences concerning day-to-day cares, participation in care, and transfer to another unit or home, were infrequently documented. However, this was seen on occasion in the communication sheets and nursing notes: "Explained transfer back to local hospital when the baby is bigger and stable. Mum not very keen on this but have explained how neonatal services are delivered through networks..." F27.

Activity focused documentation of care. Documentation of parental participation in their newborns' care was generally brief and activity focused: "Dad visited, was updated, 


\section{PARENTAL SUPPORT AND PARTICIPATION IN THE NEONATAL NOTES}

encouraged to cuddle but declined" F20T1. In the communication sheets, encouraging mother to express breast milk was frequent and commonly documented soon after admission: "I encouraged Mum to express and visit when she's well enough" F24. Similarly, in the nursing notes, entries were brief: "Mum visited and brought EBM (expressed breast milk) for baby" F12T1. In the nursing notes, where parents' participation in care was generally reported, the documentation was brief, without information regarding the kinds of care or how the parents or the infant coped: "Parents visiting and attending all the cares...." F22T1. On occasion, less routine parts of daily cares such as taking a urine sample or changing a stoma bag were documented. More specific entries were less frequent such as changing the infant's nappy or giving the infant a bath. There were frequent entries in the nursing notes of parents holding their infants: "Mum visited and cuddled the baby..."F6. Accounts of parents' experiences tended to be limited to entries from a support therapist: “...Mum remained tearful and unsure what to do, as she felt she was not being of any use to Daniel. Reassured her that she was very helpful to her son by sitting and holding his hand + talking to him" F5.

Similarly, it was rarely reported how the infant responded to cares from the parents, in the way we see in the following: "Mother visited \& updated. She participated in baby's care too, noted good suck on dummy (pacifier)" F12. Throughout the documentation of how the parents cared for their infants, the infants' names were rarely used, and the infant was frequently referred to as 'the baby'.

Outcome focused documentation of decisions. There were a few instances recorded where parents consented to procedures, with minimal information documenting parental engagement in the decision-making process; mostly vaccinations: "Father consented for baby getting appropriate vaccines" F12T2. In two instances, discussions were documented about other procedures; a shunt and administration of steroids. Parents' decisions regarding spiritual support were also documented in the communication sheets with little detail about 


\section{PARENTAL SUPPORT AND PARTICIPATION IN THE NEONATAL NOTES}

the parents' faith or spiritual preferences: "I asked mother and father if they would like a priest to come in and bless the babies - they would like it..." F24.

The documentation of decision-making conversations about LLST took place in the communication sheets. Parents' participation in the decision was documented, through their reported agreement or disagreement with the physician's recommendation: "Mother is keen to provide full intensive care until we hear from (hospital name) tomorrow.... addressed to all mother's questions" F1. Their understanding, questions and concerns were also reported as having been addressed, although without specification of what these entailed. Documentation was standardized with key components including details of the infant's poor prognosis, a team recommendation to withdraw or withhold life sustaining treatment and couched in the best interest of the infant.

\section{Professional accountability}

The organizational themes were represented by an overarching global theme, 'professional accountability', which captures the meaning of the data set as a whole (Figure 1). It refers to the way documentation is recurrently standardized within the notes, emphasizing the actions of the HCPs rather than the feelings or wishes of the family. 'Task focused reporting' captures how staff seemed to 'list' all the activities they had done, providing a record of standard tasks. Similarly, 'minimal documentation of parental role' captures how the activities of the parents are only minimally documented in terms of their occurrence and where parental preferences had implications for medical treatment. The purpose of the notes seemed to be on providing a record of important activities and decisions, rather than providing a tool for family-centered care. This standardized reporting is also reflected in the frequent use of the vague description "participated in cares", similar to the checkbox statement "encouraged parental participation in care as condition allows", as well as the 


\section{PARENTAL SUPPORT AND PARTICIPATION IN THE NEONATAL NOTES}

frequent use of the phrase "parents visited, updated", a close resemblance of the checkbox statement "keep parents up to date with care" (see Table 1).

\section{DISCUSSION}

Overall, while the documentation of activities undertaken with parents was encouraging, our results highlighted that details of this support and participation was rarely recorded within the clinical records with less than one direct reference to support per day of care. A natural limitation is that clinical records do not mirror the actual care given; indeed research has shown that parents have felt emotionally supported by HCPs (Kavanaugh, Moro, Savage, 2010; Sawyer et al., 2013). Nevertheless, our findings highlight that the frequency of the documentation of parental support by the HCPs and parents' participation in their newborns' care was limited.

The content analysis revealed that the documentation of parental participation in care and emotional support were the most frequently reported categories of support, respectively. However, the use of a checkbox to indicate encouragement of parental participation was much more frequent compared to handwritten entries referring to encouragement (506 vs 16). The absence of detailed documentations was also found by Abe et al., (2001) who found minimal reporting of emotional support in the chart reviews of infants who died in the NICU following withdrawal of care.

It was found that LLST families did not have a higher frequency of support references compared to those receiving active care. This might be explained by the critical condition of all infants in the study. Families in the active care group had a higher frequency of references to parental participation in care, which is likely to be explained by the infant's improved 


\section{PARENTAL SUPPORT AND PARTICIPATION IN THE NEONATAL NOTES}

condition and therefore the parents' ability to take part in cares. Documentation of spiritual support was higher in the LLST group; potentially related to requests for religious or spiritual ceremonies when death is likely. However, there was one LLST family with no documentation of spiritual support.

The recording of parental emotions and experiences were mainly limited to the entries of the hospital support therapists. While continual access to a trained counsellor may be recommended (BAPM, 2010), the actual provision of psychosocial support in the NICU seems to be particularly limited (Picker, 2015; POPPY, 2009). A recommendation to defer to the counsellor to coordinate or provide support to parents would therefore not be a practical solution. Furthermore, although there were trained counsellors available at the study hospital, only nine sets of clinical records out of 24 included an entry by them. Given the limited provision of psychosocial support services (Picker, 2015; POPPY, 2009) it is also worth considering the potential that the documentation of such support has in identifying and justifying a need for these services.

The wider literature has similarly found that social support is minimally recorded in patients' clinical records. In a review across a range of health care settings, the authors concluded that there was "insufficient recording of psychological, social, cultural and spiritual aspects of care," and "inadequate documentation about assessment of patients' preferences and needs for knowledge, previous health behaviour, general health perceptions and quality of life" (Wang, Hailey, Yu, 2011: 1869). Even in end-of-life care, researchers have observed low levels of recording of patient preferences and patient participation in care (Lindstrom, Gaston-Johansson, Danielson, 2010), and non-physical aspects of care more generally (Hegarty et al., 2005). While documentation may not be reflective of clinical practice, these findings, along with our own, suggest that there is a need for documentation guidance to maximise the support that is provided to patients and their families. 


\section{PARENTAL SUPPORT AND PARTICIPATION IN THE NEONATAL NOTES}

The minimal attention given to documentation of support and participation in care found in this and previous studies is perhaps unsurprising given the professionals' duty to report primarily on clinical information (GMC, 2013; NMC, 2015). Notably, communication with the patient is given some emphasis but social aspects of care more broadly are not. The standardized way of documenting LLST discussions in our data, makes visible the justification behind recommendations as well as the specific details of what the parents have agreed to. Such clear reporting ensures that professionals provide continuity of treatment. Another important issue is that the clinical record is a public record which can be called on in a court of law (Information Governance Alliance, 2016). Documentation focused on a sense of professional accountability is in some ways, then, fitted to the legal responsibilities of HCPs.

Although documentation may not capture all aspects of care that actually occur, it is nevertheless an important part of professional conduct to ensure continuity of all aspects of care (Hegarty et al., 2005). Providing insight into the parents' feelings, experiences, and preferences, is arguably one way through which HCPs can maximize an individualized, family-centered approach to care. It is recognized that family-centered approaches to care are needed to support families emotionally, enabling them to develop confidence in caring for their infants, and to support them through the stress, shock, and grief frequently described (Gooding et al., 2011; POPPY, 2009; Thurman, 1991), which has a potential to improve both family health and child development long term (O'Brien et al., 2018; Landsem, Handegard, Tunby, Ulvund, \& Ronning, 2014; Woodward et al., 2014). Furthermore, while parents have reported feeling supported emotionally in some studies (Kavanaugh et al., 2010; Sawyer et al., 2013), parents have also reported not feeling involved in discussions about their infants' care (NNAP, 2013; POPPY, 2009) and not feeling listened to (Sawyer et al., 2013). Encouraging routine, detailed documentation of these aspects of care, may promote a culture 


\section{PARENTAL SUPPORT AND PARTICIPATION IN THE NEONATAL NOTES}

of improved interaction between parents and HCPs, where the individual needs and wishes of families are discussed.

The development of national guidelines to promote more comprehensive documentation of the support given to parents, would be an important future implication of this study, especially given the absence of documentation guidelines at the neonatal unit where the study took place. The evolution of Family Integrated Care, where parents take over the role of primary caregiver is also a possible model for consideration (O'Brien et al., 2013). Within this intervention as well as the Family Nurture Intervention, the mothers keep their own records of care activities (O'Brien et al., 2013; Welch et al., 2012). This may facilitate an approach to documentation by the professionals to give more emphasis on the needs and experiences of the family and would be an interesting area of future research. Such an approach is in line with parents' reported preference for a two-way relationship with professionals (De Rouck \& Leys, 2009), but which current documentation practices do not clearly reflect.

\section{Limitations}

Although our findings are consistent with previous studies, the study was limited to one urban NICU. A larger multicentre study would also provide more statistical power in making comparisons in the distribution of documentation between the LLST group and the active care group. Whilst our audit tool was new, potentially raising issues with the trustworthiness of our findings, it was designed to capture exactly what was said, making sure that our findings were dependable. This enables the possibility for future studies to build on these findings with larger data sets, as well as making comparisons with other settings. 


\section{PARENTAL SUPPORT AND PARTICIPATION IN THE NEONATAL NOTES}

\section{CONCLUSIONS}

While there is an evident and obvious need for nurses as well as physicians to document their support to the parents and the parents' participation in care of their newborn in a way that reflects their professional accountability, this alone misses an opportunity to demonstrate inclusion and support for parents that is almost as critical to the outcome for the infants as conventional clinical interventions. Encouraging regular, detailed documentation of these aspects of care may promote a culture of improved interaction between parents and the health care team. Future research could investigate the design and use of clinical record pro formas to facilitate a more comprehensive documentation of parental preferences and experiences, in order to determine whether changes in documentation practices result in improved parental experiences. 
PARENTAL SUPPORT AND PARTICIPATION IN THE NEONATAL NOTES

\section{REFERENCES}

American Academy of Pediatrics (2003). Policy Statement: family-centered care and the pediatrician's role. Pediatrics, 112, 691-696.

Abe, N., Catlin, A., \&Mihara, D. (2001). End of life in the NICU. A study of ventilator withdrawal. MCN. The American journal of maternal child nursing, 26(3), 141-146.

Attride-Stirling, J. (2001). Thematic networks: an analytic tool for qualitative research. Qualitative Research, 1(3), 385-405.

British Association of Perinatal Medicine. (2010). Service standards for hospitals providing neonatal care (3rd edition). Retrieved from https://www.bapm.org/resources/servicestandards-hospitals-providing-neonatal-care-3rd-edition-2010

Best Beginnings. (2014). Small Wonders - Helping parents to be at the heart of their baby's care (DVD). Retrieved from http://www.bestbeginnings.org.uk/small-wonders

Blomqvist, Y. T., Rubertsson, C., \& Nyqvist, K. H. (2011). Parent-infant skin-to-skin contact; How do parent records compare to nurse records? Acta paediatrica, 100(5), 773-775.

Braun, V., \& Clarke, V. (2006). Using thematic analysis in psychology. Qualitative Research in Psychology, 3(2), 77-101.

Carter, B. S., Howenstein, M., Gilmer, M. J., Throop, P., France, D., \&Whitlock, J. A. (2004). Circumstances surrounding the deaths of hospitalized children: Opportunities for pediatric palliative care. Pediatrics, 114(3), E361-E366. doi: 10.1542/peds.2003-0654-F.

Cooper, L. G., Gooding, J. S., Gallagher, J., Sternesky, L., Ledsky, R., \& Berns, S. D. (2007). Impact of a family-centered care initiative on NICU care, staff and families. Journal of Perinatology, 27, S32-S37. doi: 10.1038/sj.jp.7211840 


\section{PARENTAL SUPPORT AND PARTICIPATION IN THE NEONATAL NOTES}

de Boer, J. C., van Blijderveen, G., \&van Dijk, G., Duivenvoorden, H.J., Williams, M. (2012). Implementing structured, multiprofessional medical ethical decision-making in a neonatal intensive care unit. Journal of Medical Ethics, 38(10), 596-601.

De Rouck, S., \& Leys, M. (2009). Information needs of parents of children admitted to a neonatal intensive care unit A review of the literature (1990-2008). Patient Education and Counselling, 76(2), 159-173.

Fereday, J., \& Muir-Cochrane, E. (2006). Demonstrating rigor using thematic analysis: A hybrid approach of inductive and deductive coding and theme development. International Journal of Qualitative Methods, 5(1), 80-92.

Gallagher, K., Porock, D., \& Edgley, A. (2010). The conecpt of 'nursing' in the abortion services. Journal of advanced nursing, 66(4), 849-857.

General Medical Coucil. (2013). Good Medical Practice. Retrieved from https://www.gmcuk.org/guidance/good_medical_practice.asp

Gooding, J. S., Cooper, L. G., Blaine, A. I., Franck, L. S., Howse, J. L., \&Berns, S. D. (2011). Family Support and Family-Centered Care in the Neonatal Intensive Care Unit: Origins, Advances, Impact. Seminars in perinatology, 35(1), 20-28.

Griffin, T. (2006). Family-centered care in the NICU. The Journal of perinatal \& neonatal nursing, 20(1), 98-102.

Harrison, H. (1993). The principles for family-centered neonatal care. Pediatrics, 92(5), 643650. 


\section{PARENTAL SUPPORT AND PARTICIPATION IN THE NEONATAL NOTES}

Hegarty, M., Hammond, L., Parish, K., Glaetzer, K., McHugh, A., Grbich, C. (2005).

Nursing documentation: non-physical dimensions of end-of-life care in acute wards. International journal of palliative nursing, 11(12), 632-636.

Hurst, I. (1993). Facilitating parental involvement through documentation. The Journal of perinatal \& neonatal nursing, 7(2), 80-90.

Information Governance Alliance. (2006). Records Management: NHS Code of Practice Part 1. Retrieved from https://digital.nhs.uk/article/1202/Records-Management-Code-of-Practicefor-Health-and-Social-Care-2016

Kavanaugh, K., Moro, T. T., \&Savage, T. A. (2010). How nurses assist parents regarding life support decisions for extremely premature infants. Journal of Obstetric, Gynecologic, and Neonatal Nursing, 39(2), 147-158.

Landsem, I. P., Handegard, B. H., Tunby, J., Ulvund, S. E.\& Ronning, J. A. (2014). Early intervention program reduces stress in parents of preterms during childhood, a randomized controlled trial. Trials, 15: 387.

Lefkowitz, D. S., Baxt, C., \&Evans, J.R. (2010). Prevalence and correlates of posttraumatic stress and postpartum depression in parents of infants in the Neonatal Intensive Care Unit (NICU). Journal of Clinical Psychology in Medical Settings, 17(3), 230-237.

Lindstrom, I., Gaston-Johansson, F., \&Danielson, E. (2010). Patients' participation in end-oflife care: Relations to different variables as documented in the patients' records. Palliative \& Supportive Care, 8(3), 247-253. doi: 10.1017/S1478951510000441

Marks, D. F., \&Yardley, L. (2004). Content and thematic analysis. In D. F. Marks \& L. Yardley (Eds.), Research Methods for Clinical and Health Psychology (pp. 56-69). London: SAGE Publications, Ltd. 


\section{PARENTAL SUPPORT AND PARTICIPATION IN THE NEONATAL NOTES}

National Institute for Health and Care Excellence. (2010). Quality standard for specialist neonatal care. Retrieved from https://www.nice.org.uk/guidance/qs4

Nursing and Midwifery Council. (2015). The Code Professional standards of practice and behaviour for nurses and midwives. Retrieved from https://www.nmc.org.uk/globalassets/sitedocuments/nmc-publications/nmc-code.pdf

National Neonatal Auditing Programme. (2013). Annual Report 2012.Retrieved from https://www.hqip.org.uk/public/cms/253/625/19/926/2013\%20NNAP\%20Annual\%20Report $\% 20(2012 \% 20$ data $) . p d f ?$ realName $=$ aAHGmC.pdf $\& v=0$

O'Brien, K., Bracht, M., Macdonell, K., McBride, T., Robson, K., O'Leary, L., Christie, K., Galarza, M., Dicky, T., Levin, A., \&Lee, S. K. (2013). A pilot cohort analytic study of Family Integrated Care in a Canadian neonatal intensive care unit. BMC Pregnancy Childbirth, 13 Suppl 1, S12. doi: 10.1186/1471-2393-13-S1-S12.

O'Brien, K., Robson, K., Bracht, M., Cruz, M., Lui, K., Alvaro, R., .. . Hales, D. (2018). Effectiveness of Family Integrated Care in neonatal intensive care units on infant and parent outcomes: a multicentre, multinational, cluster-randomised controlled trial. The Lancet Child \& Adolescent Health, 2(4), 245-254. doi:https://doi.org/10.1016/S2352-4642(18)30039-7

Picker. (2015). Parents' experiences of neonatal care: Findings from Neonatal Survey 2014: Executive Summary. Oxford: Picker Institute Europe.

POPPY. (2009). Family-centred care in neonatal units. A summary of research results and recommendations from the POPPY project. London, NCT.

Ramezani, T., Shirazi, Z.H, Sarvestani, R.S., \& Moattari, M. (2014). Family-centered care in neonatal intensive care unit: a concept analysis. International Journal of Community Based Nursing and Midwifery, 2(4), 268-278. 


\section{PARENTAL SUPPORT AND PARTICIPATION IN THE NEONATAL NOTES}

Sawyer, A., Rabe, H., Abbott, J., Gyte, G., Duley, L., \&Ayers, S., Very Preterm Birth Qualitative Collaborative, Group. (2013). Parents' experiences and satisfaction with care during the birth of their very preterm baby: a qualitative study. BJOG: An International Journal of Obstetrics and Gynaecology, 120(5), 637-643.

Shaw, R. J., Bernard, R.S., Storfer-Isser, A., Rhine, W., \&Horwitz, S.M. (2013). Parental coping in the neonatal intensive care unit. Journal of Clinical Psychology in Medical Settings, 20(2), 135-142.

Smith, V. C., SteelFisher, G.K., Salhi, C., \&Shen, L.Y. (2013). Coping with the neonatal intensive care unit experience. Journal of Perinatal and Neonatal Nursing, 26(4), 343-352.

Stacey, S., Osborn, M., \& Salkovskis, P. (2015). Life is a rollercoaster...what helps parents cope with the neonatal intensive care unit (NICU)? Journal of Neonatal Nursing, 21(4), 136141.

Sudia-Robinson, T. M., \&Freeman, S.B. (2000). Communication patterns and decision making among parents and health care providers in the neonatal intensive care unit: A case study. Heart \& Lung: The Journal of Acute and Critical Care, 29(2), 143-148.

Thurman, S. K. (1991). Parameters for establishing family-centered neonatal intensive care services. Children's Health Care: Journal of the Association for the Care of Children's Health, 20(1), 34-39.

Van der Pal, S. M., Alpay, L.L., van Steenbrugge, G.J., \& Detmar, S.B. (2014). An exploration of parents' experiences and empowerment in the care for preterm born children. Journal of Child and Family Studies, 23(6), 1081-1089.

Van Manen, M. (2014). On Ethical (In)Decisions Experienced by Parents of Infants in Neonatal Intensive Care. Qualitative Health Research, 24(2), 279-287. 


\section{PARENTAL SUPPORT AND PARTICIPATION IN THE NEONATAL NOTES}

Wang, N., Hailey, D., \&Yu, P. (2011). Quality of nursing documentation and approaches to its evaluation: a mixed-method systematic review. Journal of Advanced Nursing, 67(9), $1858-1874$.

Welch, M. G., Hofer, M. A., Brunelli, S. A., Stark, R. I., Andrews, H. F., Austin, J., \&Myers, M. M., Family Nurture Intervention Trial Group. (2012). Family nurture intervention (FNI): methods and treatment protocol of a randomized controlled trial in the NICU. BMC Pediatrics, 12, 107. doi: 10.1186/1471-2431-12-14

Woodward, L.J., Bora, S., Clar, C.A., Montgomery-Honger, A., Pritchard, V.E, Spencer, C. \& Austin, N.C. (2014). Very preterm birth: maternal experiences of the neonatal intensive care environment. Journal of Perinatology, 34 (7): 555-561. 


\section{PARENTAL SUPPORT AND PARTICIPATION IN THE NEONATAL NOTES}

\section{Figure legends}

Figure 1. Thematic overview of the global theme, organisational and basic themes representing how health care professionals documented the support provided to parents and parents' participation in their newborns' care

Figure 2. Average frequencies of types of support and parents' participation in their infant's care between infants whose families were faced with limiting life sustaining treatment (LLST) decisions and infants who were receiving active treatment documented by the health care professionals

Note: Data are presented in average frequencies of direct references by type of support or parents' participation in their infant's care documented by the health care professionals per 100 days in care 